\title{
EFEITOS DE APLICAÇÕES SUCESSIVAS DE LODO DE ESGOTO EM UM LATOSSOLO AMARELO DISTRÓFICO CULTIVADO COM CANA-DE-AÇÚCAR: CARBONO ORGÂNICO, CONDUTIVIDADE ELÉTRICA, PH E CTC(1)
}

\author{
F.C. OLIVEIRA (2), M. E. MATTIAZZO(3), C. R. MARCIANO(4) \& R. ROSSETTO(5)
}

\begin{abstract}
RESUMO
Aplicações sucessivas de lodo de esgoto em solos agrícolas podem promover alterações signi ficativas em alguns atributos quími cos dos solos. Tendo em vista essa possibilidade, o presente trabalho objetivou avaliar os efeitos de duas aplicações sucessivas de doses crescentes de lodo de esgoto sobre os teores de carbono orgânico, condutividade elétrica, pH eCTC ao pH atual de um Latossolo Amarelo distrófico cultivado com cana-de-açúcar. 0 experimento foi realizado nos anos agrícolas 1996/97 e 1997/98: no primeiro ano, além dos tratamentos calagem + adubação mineral e testemunha, foram aplicadas em área total doses equivalentes a 33, 66 e $99 \mathrm{Mg} \mathrm{ha}^{-1}$ (base seca) de lodo de esgoto. Em 1997/98, o lodo foi reaplicado em doses equivalentes a 37,74 e $110 \mathrm{Mg} \mathrm{ha}^{-1}$ (base seca). As aplicações de lodo de esgoto promoveram, em ambos os anos agrícolas, aumentos imediatos nos teores de C-orgânico, condutividade elétrica e pH do solo. A partir deste ponto, foram observados decréscimos de C-orgânico no decorrer dos dois anos agrícolas, cujos dados ajustaram-se a um modelo de cinética de primeira ordem. A redução na taxa de decréscimo, por ocasião da segunda aplicação do lodo de esgoto, evidenciou o acúmulo relativo de C-orgânico no solo, decorrente das aplicações sucessi vas do resíduo. Não houve indícios de efeitos cumulativos
\end{abstract}

(1) Parte da Tese de Doutorado do primeiro autor, apresentada ao Curso de Pós-Graduação em Sol os e Nutrição de Plantas da E scola Superior deAgricultura "Luiz de Queiroz" - ESALQ/USP. Financiado pela FAPESP. Recebido para publicação em junho de 2000 e aprovado em outubro de 2001.

(2) Engenheiro-Agrônomo, Doutor, Biossolo Agricultura \& Ambiente S.C. Ltda. Rua Edu Chaves 822, CEP 13416-020 Piracicaba (SP). E-mail: fernando@biossolidos.com.br

(3) Professora Associada, Departamento de Ciências Exatas, Escola Superior de Agricultura "Luiz de Queiroz" - ESALQ/USP. Caixa Postal 09, CEP 13418-900 Piracicaba (SP). E-mail: mmatiazo@carpa.ciagri.usp.br

(4) Professor Adjunto, Centro de Ciências e Tecnologia Agropecuária, Universidade Estadual do Norte Fluminense - UENF. Av. Alberto Lamego 2000, Horto, CEP 28015-620 Campos dos Goytacazes (RJ ). E-mail: crmarcia@bol.com.br

(5) Pesquisadora Científica, Centro de Cana-de-Açúcar, Instituto Agronômico de Campinas - IAC. Caixa Postal 28, CEP 13400-970 Piracicaba (SP). E-mail: rossetto@merconet.com.br 
sobre a condutividade elétrica em decorrência da segunda aplicação de lodo, o que evidencia estreita relação, em função do tempo, entre o comportamento dessa variável na camada de incorporação do lodo, a ocorrência de chuvas e a lixiviação de sais, demonstrada pelos aumentos na CE nas camadas subsuperficiais do solo. Para o pH, por ocasião da segunda aplicação do lodo, os incrementos foram menores do que os observados em 1996/97, evidenciando o poder de tamponamento do solo. O lodo de esgoto aumentou a capacidade de troca de cátions do solo, porém esse aumento não foi proporcional à dose aplicada, tampouco devido à segunda aplicação. As alterações na CTC foram mais bem explicadas pelas variações no pH do que pelos acréscimos de C-orgânico.

Termos de indexação: Biossólidos, solo, atributos químicos.

\author{
SUMMARY: ORGANIC CARBON, ELECTRIC CONDUCTIVITY, PH AND CEC \\ CHANGES IN A TYPIC HAPLUDOX, AFTER REPEATED \\ SLUDGE APPLICATION
}

\begin{abstract}
Repeated sewage sludge application to soils can cause changes in some soil chemical properties. The goal of this paper was to evaluate changes in soil organic carbon content, electric conductivity, pH and CEC after sewage sludge application during two years in a row. Thesoil used was as a Typic Hapludox and, after the sludgeapplication, was planted with sugarcane. The experiment had five treatments: lime +inorganic fertilization, control and sewage sludge in three levels: 33, 66 and $99 \mathrm{Mg} \mathrm{ha}^{-1}$ (dry weight basis) in the first cultivation year (1996/ 1997) and 37, 74 and $110 \mathrm{Mg} \mathrm{ha}^{-1}$ in the following year (1997/ 1998). There was an increase in soil organic carbon content, electric conductivity, pH and CEC values, measured 360 days after thesludge applicati on each year. The decreasein soil organic carbon level in the period was adjusted to a first order model kinetics. Soil organic carbon accumulati on was also observed and was dueto repeated sludge application. There was no cumulative effect on soil el ectric conductivity for thesecond sewagesludgeapplication. This allows to conclude that rainfall played an essential role over ion leaching during that period. I ncreased electric conductivity could beobserved in thelower soil depth. Theincrease in soil pH, after the second sludge application, was lower than that observed after the first one, what indicated thebuffer capacity of thesoil and al kal inity of thewaste. Therewas an increase in soil CEC, but it was not related to the sludge leve applied or to the second application. The changes in CEC were explained based on changes in $\mathrm{pH}$ rather than in organic carbon.
\end{abstract}

Index terms: Biosolids, soil, chemical atributes.

\section{NTRODUÇÃO}

Alguns dos efeitos causados pela apl icação de lodo de esgoto em solos agrícolas estão diretamente relacionados com a persistência da carga orgânica do resíduo nestes sol os. Se parte do carbono orgânico presente no lodo for resistente à degradação, seu teor no sol o aumentará ao longo de sucessi vas aplicações, podendo proporcionar alterações significativas em algumas propriedades químicas e físicas desse solo (Clapp et al., 1986; Metzger \& Yaron, 1987).

Os incrementos e a conservação do teor de carbono orgânico de solos, em decorrência dessa prática, podem ser atribuídos às taxas de degradação do lodo e aos fatores que as determinam. Em solos sob cl ima temperado, tais incrementos são possíveis e têm sido comprovados por diversos trabalhos (E pstein et al., 1976; Logan et al., 1997).

Trabalhos efetuados em sol os tropicais mostraram que efeitos do lodo de esgoto sobre o C-orgânico dos sol os, quando ocorrem, são temporários (Mel o et al., 1994; Silva, 1995). Resultados obtidos por Marques(1996) revelaram que somente em taxas el evadas de aplicações seria possível uma ação mais prolongada do lodo de esgoto sobre os teores de Corgânico dos solos. Esse autor observou efeito crescente sobre os teores de C-orgânico de um Latossolo Vermelho-Escuro, até um ano após a aplicação de 40, 80 e $160 \mathrm{Mg} \mathrm{ha}^{-1}$ (74 \% de umidade) de lodo de esgoto. 
O simples aumento no teor de C-orgânico pode não significar benefícios ao sistema solo-planta. Hohla et al. (1978) observaram, num solo que recebeu, durante seis anos, aplicações sucessivas de lodo de esgoto anaeróbio, que os teores de C-orgânico aumentaram de 9,5 para $22,9 \mathrm{~g} \mathrm{~kg}^{-1}$; entretanto, estudos de fracionamento revelaram que do Corgânico presente no solo tratado, 10,9\% correspondia a C-carboidrato e $11,9 \%$ a óleos e graxas, enquanto, no sol o-testemunha, estas frações eram, respectivamente, de 18,9 e $1,67 \%$. I sto demonstra que é preciso conhecer melhor a qualidade do carbono orgânico persistente e principalmente seus efeitos a longo prazo sobre as características químicas e físicas do sol o que são de interesse para fins agronômicos e ambientais.

Medidas da condutividade elétrica são freqüentementeutilizadas para avaliar a concentração de sais solúveis no solo. De acordo com a Sociedade Americana de Ciência de Solo (Richards, 1954), valores de condutividade elétrica, em extrato de saturação, maiores que $2.000 \mu \mathrm{S} \mathrm{cm}-1$ caracterizam solos salinos. Nesses casos, o crescimento e o desenvolvimento das plantas são diretamente afetados pela ocorrência de toxidez de alguns íons, desequilíbrios nutricionais e, principal mente, pelas dificuldades na absorção de água e nutrientes ocasionadas pelo aumento da pressão osmótica da solução do solo (Marschner, 1995).

A aplicação de lodo de esgoto em solos agrícolas pode aumentar a condutividadeel étrica desses solos, considerando os altos teores de sais presentes no resíduo (Epstein et al., 1976; Stark \& Clapp, 1980; Harding et al ., 1985; Logan et al., 1997; Anjos, 1999). Dependendo das condi ções de clima, tipo de solo, da composição, taxa e freqüência de aplicações, o emprego do lodo de esgoto pode provocar efeitos sazonais de salinização, prejudicando, assim, o crescimento e o desenvolvimento das plantas (Bevacqua \& Mellano, 1994).

Outro aspecto importante quando da utilização agrícola delodo de esgoto é seu efeito sobre o pH dos solos, cuja extensão é dependente do tipo de tratamento que o resíduo recebeu, taxa efreqüência de aplicação do lodo e das propriedades do sol o, como textura e capacidade de tamponamento (Clapp et al., 1986).

Aumentos na capacidade de troca de cátions, em solos tratados com lodo de esgoto, foram relatados por diversos autores, dentre eles, Epstein et al. (1976), Melo et al. (1994) e Silva (1995). No entanto, nesses trabalhos, a CTC foi avaliada pela soma de bases, o que pode levar, dependendo da taxa de aplicação, a valores superestimados graças às el evadas concentrações de cálcio que, freqüentemente, ocorrem no lodo de esgoto.

Atualmente, para determinação da CTC em solos, tem sido recomendado pela American Society of Agronomy (Sumner \& Miller, 1996) o método proposto por Gillman \& Sumpter (1986), por possibilitar a quantificação da CTC ao pH atual do solo, que é a forma mais próxima das condições naturais de campo. Esse procedimento é visto como o mais adequado para os solos intemperizados das regiões tropicais, onde a CTC é altamente dependente do pH (Rodella, 1996).

O objetivo deste trabalho foi avaliar os efeitos causados por aplicações sucessivas de doses crescentes de lodo de esgoto sobre os teores de carbono orgânico, condutividade el étrica, pH eCTC ao $\mathrm{pH}$ atual de um Latossolo Amarelo distrófico cultivado com cana-de-açúcar.

\section{MATERIAL E MÉTODOS}

O experimento foi realizado nos anos agrícolas de 1996/97 e 1997/98, em condições de campo, numa área plana de Latossolo Amarelo distrófico, selecionada no setor mais el evado da paisagem da Estação Experimental do Instituto Agronômico de Campinas, em Piracicaba (SP). O clima, de acordo com a classificação de Köppen, é do tipo Cwa: subtropical com inverno seco (Setzer, 1966). Os parâmetros climáticos apresentam as seguintes médias anuais: (a) precipitação: $1.253 \mathrm{~mm}$; (b) temperatura: $21,1^{\circ} \mathrm{C}$; (c) umidade relativa do ar: $74 \%$; (d) vel ocidade do vento: $2,2 \mathrm{~m} \mathrm{~s}^{-1}$. As principais características químicas e físicas do solo são apresentadas no quadro 1.

Foram empregadas duas remessas de lodo de esgoto anaeróbio semidesidratado, obtidas junto à Estação de Tratamento de Esgotos de Barueri SABESP, Barueri (SP). Algumas características químicas dos resíduos, determinadas de acordo com Eaton et al. (1995), encontram-se no quadro 2.

Estabeleceram-secinco tratamentos distribuídos num delineamento em blocos casualizados com quatro repetições, os quais foram aplicados em parcelas experimentais de $100 \mathrm{~m}^{2}$ cultivadas com cana-de-açúcar em ciclo anual. Tais tratamentos foram os seguintes: calagem + adubação mineral (CM); testemunha (T); lodo de esgoto nas doses $A$ (La), B (Lb) e C (LC).

$\mathrm{O}$ tratamento $\mathrm{CM}$ constou, além da calagem e adubação de plantio (70 kg ha-1 de N) em 1996/97, da aplicação de $120 \mathrm{~kg} \mathrm{ha}^{-1}$ de nitrogênio em cobertura (Spironello et al., 1996) na 1a soqueira, ano agrícola 1997/98. A dose B (Lb) de lodo de esgoto foi definida de acordo com a quantidade máxima de metais pesados possível de ser adicionada anual mente em sol os agrícolas, conforme os critérios preconizados pela Norma 40 CFR (Code Federal Regulations) Part 503 da USEPA (1993); a dose A ( $L$ a) foi a metade e a dose C ( $L C), 1,5$ vez $L b$. Desta forma, em base seca, as respectivas doses do resíduo foram: (a) 1ạ aplicação (1996/97): A =33, B = 66 e 
Quadro 1. Características químicas e físicas do Latossolo Amarelo distrófico antes da instalação do experimento

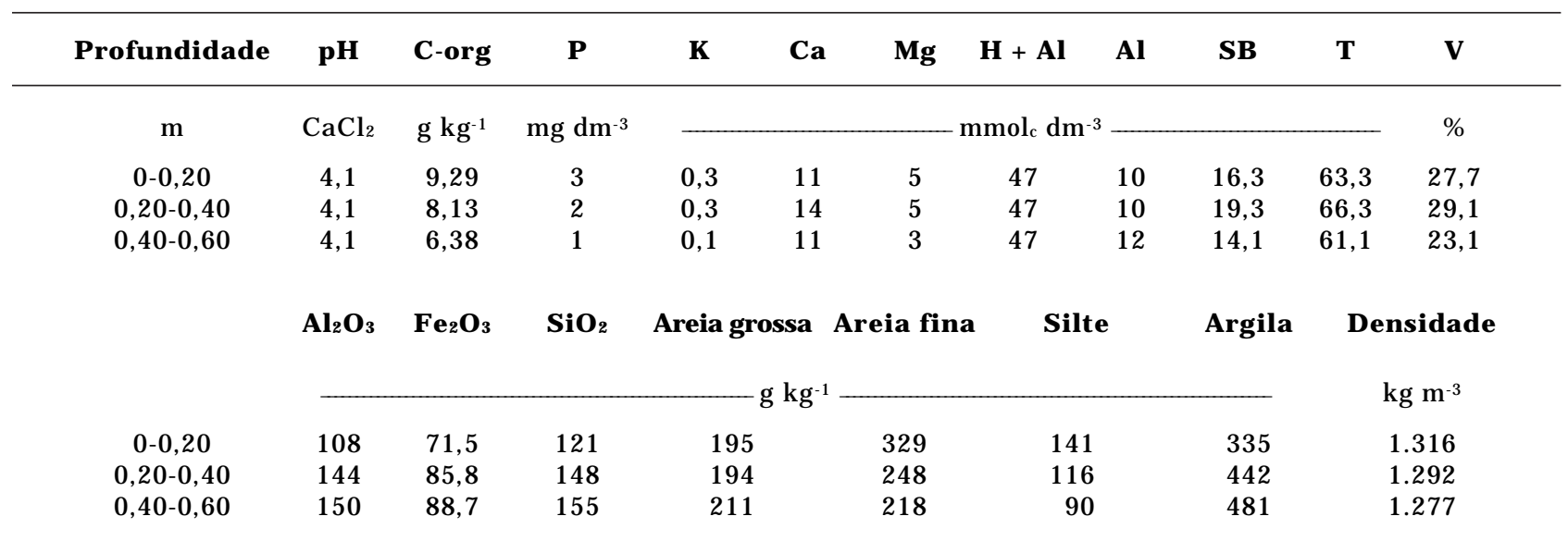

(1) $2 \mathrm{~mm} \geq$ Areia grossa $>0,5 \mathrm{~mm} \geq$ Areia fina $>0,05 \mathrm{~mm} \geq$ Silte $>0,002 \mathrm{~mm} \geq$ Argila.

$\mathrm{C}=99 \mathrm{Mg} \mathrm{ha}^{-1}$, o equivalentea 6,8; 13,7e20,6 $\mathrm{Mg} \mathrm{ha}^{-1}$ deC-orgânico; (b) 2a aplicação (1997/98): A = 37, B = 74 e $\mathrm{C}=110 \mathrm{Mg} \mathrm{ha}^{-1}$, o equivalente a $6,8,13,6 \mathrm{e}$ 20,4 Mg ha-1 de C-orgâni co, respectivamente. Os resíduos foram aplicados na superfície do solo em área total, com distribuição manual dentro das parcel as e incorporação, após um período de sete dias de pré-secagem, na camada de 0-0,2 m, com enxada rotativa (1997/98, incorporação apenas nas entrelinhas da cultura).

Amostras compostas de solo, col etadas dentro da área útil $\left(25,2 \mathrm{~m}^{2}\right.$ centrais) de cada parcela experimental, foram formadas por cinco amostras simples retiradas nas entrelinhas da cultura. Na camada de 0-0,2 m foram coletadas amostras, dentro de cada ano agrícola, 0, 30, 60, 90, 150, 210, 270 e 360 dias após a incorporação do lodo de esgoto (DAIL). Aos 360 DAIL, nos dois anos de experimentação, também foram col etadas amostras representativas das camadas de 0,2-0,4, 0,4-0,6 e 0,6$0,8 \mathrm{~m}$. Todas as amostras foram secas em estufa de circulação forçada de ar a $60^{\circ} \mathrm{C}$, destorroadas e passadas por peneira ABNT no $16(1,19 \mathrm{~mm}$ de malha) com objetivo principal de eliminar, ao máximo, a presença de pequenas raízes.

As avaliações de carbono orgânico (C-orgânico), condutividade elétrica (CE), pH e capacidade de troca de cátions (CTC) do sol o foram realizadas nas amostras dos dois anos agrícolas. Os teores de Corgânico foram determinados, na camada de 0-0,2 m, aos $0,30,60,90,150,210,270$ e 360 DAIL. Tais determinações foram realizadas por método volumétrico de oxirredução em amostras de 3,00 g de solo, seguindo, em linhas gerais, o método proposto por Walkley \& Black (1934). A taxa de degradação da carga orgânica do lodo de esgoto foi estimada pelo decréscimo do C-orgânico presente no solo, por meio da aplicação de modelo cinético de primeira ordem (Rodella, 1996) aos dados médios dos chamados incrementos de carbono. A variável incremento de carbono expressa oteor de C-orgânico remanescente no solo devido ao tratamento e foi obtida, ao longo do período estudado, pela diferença entre o teor de C-orgânico nas parcel as tratadas com lodo de esgoto e oteor presentenas testemunhas. Tal procedimento pode ser resumido pela seguinte expressão:

$$
\mathrm{iC}=\mathrm{C}_{\text {trat }}-\mathrm{C}_{\text {test }}
$$

em que

iC =incremento de carbono em $\mathrm{g} \mathrm{kg}^{-1}$;

$\mathrm{C}_{\text {trat }}=$ teor de C-orgânico nas parcelas tratadas com lodo de esgoto;

$\mathrm{C}_{\text {test }}=$ teor de C-orgânico nas parcelastestemunhas.

As determinações de $\mathrm{CE}$ e $\mathrm{pH}$ foram realizadas nas amostras col etadas na camada de 0-0,2 m, aos 30, 60, 90, 150, 210, 270 e 360 DAIL. A CE também foi determinada nas amostras de sol o, col etadas em profundidade, aos 360 DAIL. Tais determinações foram efetuadas em extrato solo-água, na relação 1:1(v/v), com leitura em condutivímetro com célula de $1 \mathrm{~cm}$. As determinações de $\mathrm{pH}$ foram feitas em extratos de $\mathrm{CaCl}_{2} 0,01 \mathrm{~mol} \mathrm{~L}^{-1}$, com relação solosolução 1:2,5 (v/v). A CTC foi obtida nas amostras, col etadas na camada de 0-0,2 m, aos 30, 90, 150, 270 e 360 DAIL. Essas determinações foram realizadas pel o método proposto por Gillman \& Sumpter (1986), utilizando soluções não tamponadas.

As análises estatísticas foram feitas, separadamente, para cada ano experimental, em del ineamento com parcelas subdivididas, sendo as parcelas constituídas pel os tratamentos ( $T, L a, L b$ e $L c)$ e as 
subparcelas, pelas épocas de col eta das amostras de solo (DAIL). Foi aplicado o teste $F$ e, quando constatada interação significativa, as médias das variáveis C-orgânico, CE, pH e CTC foram testadas, dentro de épocas de amostragem etratamentos, por modelos de regressão polinomial de 10 e $2 \circ$ grau. Para a variável incremento de carbono, considerando os efeitos significativos das causas de variação, foram realizados ajustes de funções exponenciais do tipo $y=a e^{-b x}$. Também foi feita análise de correlação linear simples entre valores de $\mathrm{CTC}$ e pH e entre CTC eC-orgânico. O tratamento CM foi considerado apenas nas análises de correlação entre CTC e pH.

\section{RESULTADOS E DISCUSSÃO}

\section{Carbono orgânico do solo}

Os teores deC-orgânico apresentaram, em todas as épocas de amostragem, nos dois anos agrícolas, aumentos lineares, dependendo das doses aplicadas de lodo de esgoto (Quadro 3). Tomando como base o tratamentoT, verificou-se que, aos $360 \mathrm{DAIL}$, no ano agrícola 1996/97, houve aumentos de 13, 14 e $15 \%$

Quadro 2. Composição química parcial das duas remessas de lodo de esgoto utilizadas no experimento ${ }^{(1)}$. Médias de três amostras compostas retiradas de cada remessa de lodo

\begin{tabular}{|c|c|c|}
\hline \multirow{2}{*}{ Atributo analisado } & \multicolumn{2}{|c|}{ Lodo de esgoto } \\
\hline & 1996 & 1997 \\
\hline $\mathrm{pH}\left(\mathrm{H}_{2} \mathrm{O}, 1: 2,5\right)$ & 12,25 & 8,50 \\
\hline Poder de neutralização (\% $\mathrm{CaCO}_{3}$ eq.) & 40,36 & 31,44 \\
\hline Carbono orgânico $\left(\mathrm{g} \mathrm{kg}^{-1}\right)$ & 207,88 & 184,85 \\
\hline $\mathrm{N}$-total $\left(\mathrm{g} \mathrm{kg}^{-1}\right)$ & 25,58 & 21,71 \\
\hline $\mathrm{N}-\mathrm{NO}_{3}^{-}+\mathrm{N}-\mathrm{NH}_{4}{ }^{+}\left(\mathrm{g} \mathrm{kg}^{-1}\right)$ & 3,19 & 2,60 \\
\hline Relação C/N-total & 8,13 & 8,51 \\
\hline СТC a pH 7,0 (mmol $\left.\mathrm{kg}^{-1}\right)$ & 436,55 & 375,25 \\
\hline P-total $\left(\mathrm{g} \mathrm{kg}^{-1}\right)$ & 11,20 & 11,16 \\
\hline K-total $\left(\mathrm{g} \mathrm{kg}^{-1}\right)$ & 1,06 & 0,97 \\
\hline Ca-total $\left(\mathrm{g} \mathrm{kg}^{-1}\right)$ & 170,31 & 132,10 \\
\hline Mg-total $\left(\mathrm{g} \mathrm{kg}^{-1}\right)$ & 10,63 & 2,70 \\
\hline S-total $\left(\mathrm{g} \mathrm{kg}^{-1}\right)$ & 8,49 & 10,77 \\
\hline Na-total ( $\left.\mathrm{g} \mathrm{kg}^{-1}\right)$ & 0,76 & 0,71 \\
\hline Cd-total $\left(\mathrm{mg} \mathrm{kg}^{-1}\right)$ & 28,4 & 16,0 \\
\hline Cr-total (mg kg-1) & 385,0 & 386,0 \\
\hline Cu-total (mg kg-1) & 784,3 & 534,0 \\
\hline Ni-total (mg kg-1) & 238,6 & 286,0 \\
\hline Pb-total (mg kg-1) & 152,8 & 171,0 \\
\hline Zn-total (mg kg-1) & $1.568,5$ & $1.649,0$ \\
\hline
\end{tabular}

(1) Exceto o pH, cuja determinação foi feita a partir do material úmido, os demais resultados são expressos com base no material seco. nos teores de C-orgânico, proporcionados, respectivamente, pelas doses de 33, 66 e $99 \mathrm{Mg} \mathrm{ha}^{-1}$ de lodo de esgoto. Aos $360 \mathrm{DAIL}$, ano agrícola 1997/98, tais aumentos foram de 17, 25 e $43 \%$, respectivamente, para as doses de 37, 74 e $110 \mathrm{Mg} \mathrm{ha}^{-1}$, cerca de 10, 17 e $33 \%$ de acúmulo em relação aos teores de C-orgânico observados ao final do ano anterior. Estes dados revel am, de maneira geral, queo lodo de esgoto foi capaz de proporcionar aumentos significativos nos teores de C-orgânico do solo, indicando a possibilidade de incrementos maiores por ocasião de aplicações sucessivas do resíduo.

Tais incrementos também foram observados por autores que desenvolveram seus experimentos em solos sob clima temperado (Epstein et al., 1976; Logan et al., 1997). Por outro lado, com base nos resultados apresentados por Melo et al. (1994), Silva (1995) e Marques (1996), é possível que, no presente trabalho, os efeitos observados sejam devidos às doses e à freqüência das aplicações. Dessa forma, em doses menores que 33-37 $\mathrm{Mg} \mathrm{ha}^{-1}\left(6,8 \mathrm{Mg} \mathrm{ha}^{-1}\right.$ de C-orgânico) provavelmente seriam necessárias várias aplicações anuais e sucessivas até que seus efeitos sobre o C-orgânico do sol o fossem detectados por um período superior ou igual a um ano.

Os teores deC-orgânico foram influenciados pela interação de tratamentos e épocas de amostragem do solo. Esperava-se que esta interação fosse devida ao decréscimo dos teores de carbono em função do tempo ocorrido da aplicação, o que foi verdadeiro apenas para Lb e Lc, no ano agrícola 1997/98. No entanto, pode-se observar (Quadro 3), no decorrer das épocas deamostragem do solo, um comportamento crescente dos teores de C-orgânico no tratamentoT. Esses acréscimos foram mais expressivos para o primeiro ano agrícola. O teor de C-orgânico apresentado original mente pel o Latossolo Amarelo distrófico, antes da instalação do experimento, era de 9,29 $\mathrm{g} \mathrm{kg}^{-1}$ (Quadro 1).

Dessa forma, o menor val or observado para esta variável no tempo zero do ano agrícola 1996/97 é justificado pelas operações de preparo do sol o antes da aplicação do lodo de esgoto. Tais operações, que constaram de subsolagem, uma aração e uma gradagem, promoveram uma inversão de camadas, aflorando o solo da camada abaixo de 0,2 m, com menor teor de C-orgânico (Quadro 1). Outra possibilidade a ser considerada é o estímulo à degradação de parte do C-orgânico nativo do solo pela aeração proporcionada por tais operações. É importante notar que os teores de C-orgânico da testemunha retornaram aos seus valores originais somente aos 24 meses do preparo inicial do solo.

Em virtude destas observações, foi calculada a variável incremento de carbono (iC) que permitiu melhor comparação do decréscimo do carbono subseqüente às aplicações de lodo nos dois anos agrícolas, da sua taxa de degradação e conseqüente potencial de acúmulo no solo. 
Quadro 3. Carbono orgânico do solo, determinado nos tratamentos com doses crescentes de lodo de esgoto, em diversas épocas de amostragem, nos anos agrícolas 1996/97 e 1997/98

\begin{tabular}{|c|c|c|c|c|c|c|}
\hline \multirow{2}{*}{ DAIL (1) } & \multicolumn{4}{|c|}{ Dose de lodo de esgoto } & \multicolumn{2}{|c|}{ Termo de regressão $\left(\mathbf{R}^{2}\right)$} \\
\hline & $\mathbf{T}^{(2)}$ & La & Lb & Lc & Linear & Quadrático \\
\hline & \multicolumn{4}{|c|}{$\mathrm{g} \mathrm{kg}^{-1}$} & & \\
\hline \multicolumn{7}{|c|}{ Ano agrícola 1996/97 } \\
\hline 0 & 7,16 & 9,12 & 10,67 & 12,37 & $0,99 * *$ & ns \\
\hline 30 & 7,09 & 8,48 & 9,14 & 9,90 & $0,97 * *$ & ns \\
\hline 60 & 6,94 & 8,29 & 8,84 & 9,61 & $0,96 * *$ & ns \\
\hline 90 & 7,58 & 8,77 & 9,61 & 10,67 & $0,99 * *$ & ns \\
\hline 150 & 8,74 & 10,03 & 10,49 & 11,70 & $0,97 * *$ & ns \\
\hline 210 & 8,39 & 9,89 & 9,99 & 10,34 & $0,79 * *$ & ns \\
\hline 270 & 8,86 & 9,95 & 9,98 & 10,41 & $0,83^{* *}$ & ns \\
\hline 360 & 8,86 & 10,04 & 10,07 & 10,19 & $0,69 *$ & ns \\
\hline \multicolumn{7}{|c|}{ Termo de regressão $\left(R^{2}\right)$} \\
\hline Linear & $0,79 * *$ & $0,63^{* *}$ & ns & ns & - & - \\
\hline Quadrático & $0,85^{*}$ & ns & ns & ns & - & - \\
\hline \multicolumn{7}{|c|}{ Ano agrícola 1997/98 } \\
\hline 0 & 8,57 & 11,79 & 12,88 & 15,95 & $0,97 * *$ & ns \\
\hline 30 & 8,86 & 11,83 & 12,81 & 14,97 & $0,97 * *$ & ns \\
\hline 60 & 8,72 & 11,00 & 11,68 & 14,10 & $0,96 * *$ & ns \\
\hline 90 & 8,87 & 11,06 & 11,85 & 14,00 & $0,97 * *$ & ns \\
\hline 150 & 8,98 & 11,33 & 11,65 & 14,01 & $0,94 * *$ & ns \\
\hline 210 & 8,99 & 11,03 & 11,72 & 14,33 & $0,96 * *$ & ns \\
\hline 270 & 9,42 & 11,37 & 12,05 & 13,82 & $0,97 * *$ & ns \\
\hline 360 & 9,48 & 11,06 & 11,84 & 13,53 & $0,98 * *$ & ns \\
\hline \multicolumn{7}{|c|}{ Termo de regressão $\left(\mathrm{R}^{2}\right)$} \\
\hline Linear & $0,87^{*}$ & ns & $0,28 *$ & $0,56 * *$ & - & - \\
\hline Quadrático & ns & ns & $0,62^{*}$ & 0,68 * & - & - \\
\hline
\end{tabular}

${ }^{(1)}$ Dias após a incorporação do lodo de esgoto. ${ }^{(2)} \mathrm{T}=0, \mathrm{La}=33, \mathrm{Lb}=66, \mathrm{Lc}=99 \mathrm{Mg} \mathrm{ha}^{-1}$ em 1996/97 eT=0, La = 37, Lb =74, Lc = $110 \mathrm{Mg} \mathrm{ha}^{-1} \mathrm{em} 1997 / 98$. *,**, ns indicam, respectivamente, que os termos de regressão linear ou quadrática foram significativos a $\mathrm{P} \leq 0,05, \mathrm{P} \leq 0,01$ ou não-significativos pelo teste $\mathrm{F}$.

A análise de variância para incremento de carbono apontou, no ano agrícola 1996/97, interação significativa de doses de lodo de esgoto e épocas de amostragem, evidenciando o comportamento diferenciado entre doses. Para o segundo ano, foram verificados efeitos significativos de doses e épocas de amostragem, não havendo interação desses fatores.

De maneira geral, para os dois anos agrícolas, verificou-se que o decréscimo do C-orgânico ajustouse a um modelo de cinética de primeira ordem (Figura 1). Em 1997/98, verificou-se melhor ajuste para um model o composto por duas etapas queforam delimitadas entre os 150 e 210 DAIL (Figura 1), período de inverno e condições de seca. A relação entre as constantes mostrou que, na primeira etapa, a velocidade de degradação foi 42 vezes maior que na segunda.

Com base no model o matemático adotado, pôdese inferir, portanto, que o lodo de esgoto teria apresentado uma fase inicial de degradação mais rápida, seguida por outra de estabilização progressiva. A maior velocidade de degradação no período inicial seria explicada pelo ataque microbiano àquelas substâncias orgânicas mais facil mente degradáveis que restaram do tratamento biológico dos esgotos, como a biomassa microbiana composta de proteínas e carboidratos, ao passo que, na fase final, a menor vel ocidade de degradação seria atribuída às substâncias recal citrantes.

Miller (1974) e Terry et al. (1979ab) observaram este mesmo comportamento para lodos anaeróbios em ensaios de respirometria em condições de laboratório. Em condições de campo, utilizando método semelhante ao do presente trabalho, esse comportamento também foi verificado por Logan et al. (1997).

Para o primeiro ano agrícola, as taxas de decréscimo foram estimadas em 65 e $73 \%$, respectivamente, para Lb e Lc. Estas taxas podem ser consideradas como uma estimativa da taxa de degradação da carga orgânica do lodo de esgoto. É 


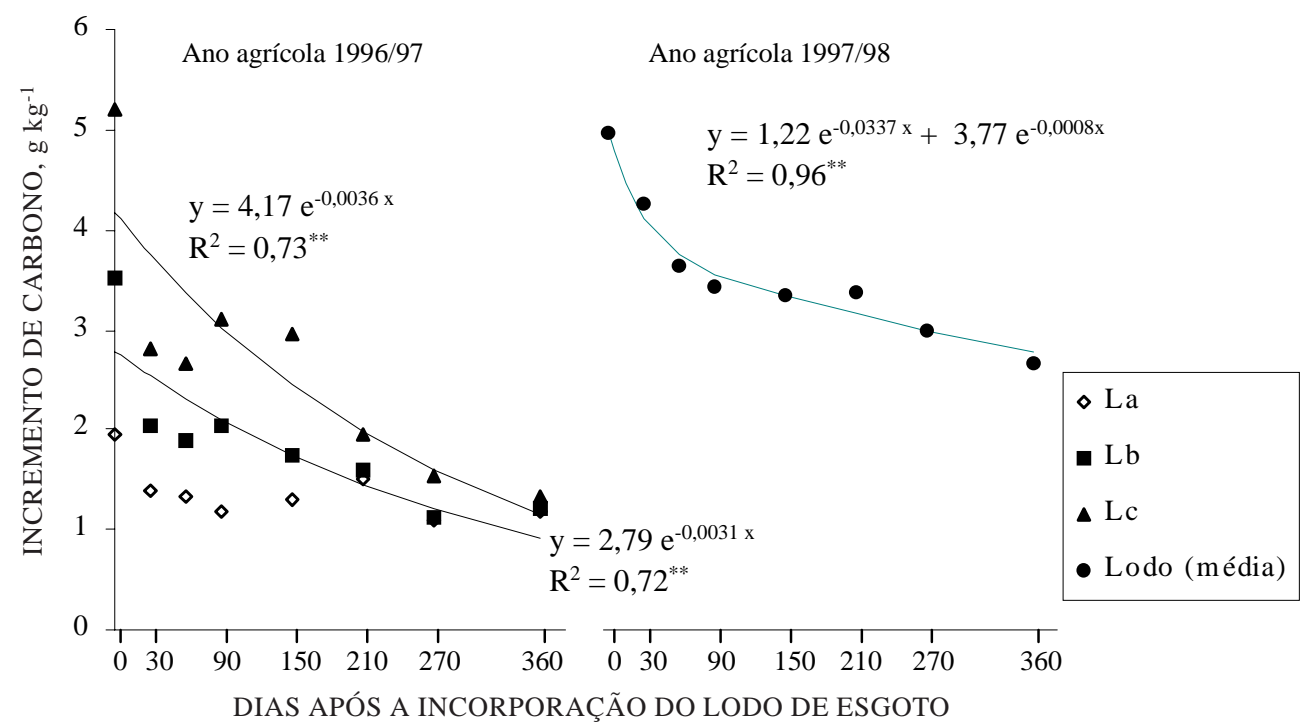

Figura 1. Decréscimo do incremento de carbono (iC) do solo em função do tempo, nos anos agrícolas de 1996/97 e 1997/98. (** significativo a $\mathrm{P} \leq 0,01$ pelo teste $\mathrm{F}$ ).

La = lodo dose A; Lb = lodo dose B; Lc = lodo dose C e Lodo = média de La, Lb e Lc.

importante salientar que, neste ano, para diminuir ao máximo a interferência de plantas invasoras, foram necessárias três operações de cultivo mecânico. Assim, as altas taxas de degradação estimadas para o lodo de esgoto podem ser justificadas por um aumento na oxidação do Corgânico, estimulado pelo revolvimento e conseqüente oxigenação do solo na sua camada superficial. Para La, não houve ajuste significativo ao model o matemático adotado.

A pós a segunda aplicação do resíduo, ano agrícola 1997/98, a taxa média de decréscimo do carbono foi estimada em $44 \%$. Entretanto, não foi possível confirmar uma diminuição na taxa de degradação do resíduo, uma vez que a taxa de decréscimo obtida nesta ocasião incluiu o carbono recalcitrante acumulado no solo devido à aplicação anterior. O fato de nãoter havido, nesteano, operação mecânica que revolvesse o solo certamente colaborou para diminuir o decréscimo do carbono. Entretanto, não devem ser descartadas as possibilidades da ocorrência de efeitos inibitórios sobre microrganismos organotróficos, causados pelo possível acúmulo de metais pesados esubstâncias orgânicas recalcitrantes e tóxicas presentes no lodo de esgoto. Tais possibilidades devem ser avaliadas cuidadosamente em outros estudos.

As taxas de decréscimo do carbono encontradas no presentetrabal ho podem ter sido superestimadas basicamente por duas razões: possibilidade de perdas, por meio da lixiviação, de substâncias orgânicas solúveis da camada de incorporação do resíduo; aumento da degradação do C-orgânico nativo do solo com a aplicação do lodo de esgoto, fenômeno conhecido como "efeito priming", observado por diversos autores, dentre el es Terry et al. (1979a).

Nas condições do presente trabalho, considerando as taxas e a freqüência das aplicações do lodo de esgoto, evidenciou-se que parte do C-orgânico presente no lodo foi resistente à degradação no sol o. Essa observação é concordante com diversos estudos realizados em condições controladas de laboratório, os quais evidenciaram a relativa resistência à degradação no solo da carga orgânica de lodos anaeróbios (Miller, 1974; Agbin et al., 1977; Terry et al., 1979a). Esta resistência, por sua vez, éatribuída essencialmente ao tratamento de estabilização biológica que o lodo de esgoto recebe nas estações de tratamento de esgotos (Demuynck et al ., 1985), o que confere presença significativa na sua fração orgânica de compostos estáveis, tais como: lignina, celulose, lipídeos, substâncias húmicas, graxas, ceras, óleos e resinas (Pagliai et al., 1981; Clapp et al., 1986).

\section{Condutividade elétrica e pH}

Nos dois anos agrícolas, a CE do solo foi influenciada significativamente pela interação de tratamentos e épocas de amostragem. De maneira geral, a aplicação de lodo de esgoto aumentou a CE do solo (Quadro 4).

No ano agrícola 1996/97, na maioria das épocas de amostragem, as doses empregadas do resíduo proporcionaram efeito quadrático sobre a variável em questão. No ano seguinte, após a segunda aplicação, com exceção dos val ores determinados aos 30 DAIL, foi constatado que a CE aumentou linearmente com as doses empregadas. Este 
Quadro 4. Condutividade elétrica do solo, determi nada na camada de 0-0,2 m, nos tratamentos com doses crescentes de lodo de esgoto, em diversas épocas de amostragem, nos anos agrícolas 1996/97 e 1997/98

\begin{tabular}{|c|c|c|c|c|c|c|}
\hline \multirow{2}{*}{ DAIL (1) } & \multicolumn{4}{|c|}{ Dose de lodo de esgoto } & \multicolumn{2}{|c|}{ Termo de regressão $\left(R^{2}\right)$} \\
\hline & $\mathbf{T}^{(2)}$ & $\mathbf{L a}$ & $\mathbf{L} \mathbf{b}$ & L c & Linear & Quadrático \\
\hline & \multicolumn{4}{|c|}{$\mu \mathrm{S} \mathrm{cm}^{-1}$} & & \\
\hline \multicolumn{7}{|c|}{ Ano agrícola 1996/97 } \\
\hline 30 & 101,6 & 1112,5 & 1022,0 & 1272,8 & $0,70 * *$ & $0,88 * *$ \\
\hline 60 & 79,4 & 464,3 & 516,0 & 606,0 & $0,82 * *$ & $0,96 * *$ \\
\hline 90 & 115,4 & 670,5 & 586,8 & 749,0 & $0,68 * *$ & $0,84 * *$ \\
\hline 150 & 107,0 & 517,0 & 484,8 & 600,8 & $0,73 * *$ & $0,88 * *$ \\
\hline 210 & 116,9 & 497,3 & 407,0 & 556,3 & $0,66 * *$ & $0,78 * *$ \\
\hline 270 & 62,9 & 246,0 & 280,5 & 368,3 & $0,91 * *$ & ns \\
\hline 360 & 73,9 & 294,8 & 336,0 & 370,5 & $0,81 * *$ & $0,97 * *$ \\
\hline \multicolumn{7}{|c|}{ Termo de regressão $\left(R^{2}\right)$} \\
\hline Linear & ns & $0,59 * *$ & $0,61^{* *}$ & $0,62 * *$ & - & - \\
\hline Quadrático & ns & $0,67 * *$ & $0,78^{* *}$ & $0,73^{* *}$ & - & - \\
\hline \multicolumn{7}{|c|}{ Ano agrícola 1997/98 } \\
\hline 30 & 127,3 & 530,5 & 569,5 & 716,3 & $0,86 * *$ & $0,94 *$ \\
\hline 60 & 79,7 & 309,0 & 336,0 & 454,0 & $0,90 * *$ & ns \\
\hline 90 & 89,8 & 468,5 & 555,8 & 712,8 & $0,91 * *$ & ns \\
\hline 150 & 92,2 & 454,8 & 499,3 & 800,0 & $0,93 * *$ & ns \\
\hline 210 & 61,8 & 289,5 & 280,0 & 534,8 & $0,96 * *$ & ns \\
\hline 270 & 80,0 & 379,5 & 472,8 & 672,8 & $0,96 * *$ & ns \\
\hline 360 & 70,8 & 156,3 & 252,6 & 301,1 & $0,99 * *$ & ns \\
\hline \multicolumn{7}{|c|}{ Termo de regressão $\left(R^{2}\right)$} \\
\hline Linear & ns & $0,55^{* *}$ & $0,35^{* *}$ & $0,27 * *$ & - & - \\
\hline Quadrático & ns & $0,59 *$ & ns & $0,52 * *$ & - & - \\
\hline
\end{tabular}

(1) Dias após a incorporação do lodo de esgoto. ${ }^{(2)} \mathrm{T}=0, \mathrm{La}=33, \mathrm{Lb}=66, \mathrm{Lc}=99 \mathrm{Mg} \mathrm{ha}^{-1}$ em 1996/97 e T =0, La = 37, Lb =74, Lc = $110 \mathrm{Mg} \mathrm{ha}^{-1} \mathrm{em} 1997 / 98$. *,**, ns indicam, respectivamente, que os termos de regressão linear ou quadrática foram significativos a $\mathrm{P} \leq 0,05, \mathrm{P} \leq 0,01$ ou não-significativo pelo teste $\mathrm{F}$.

comportamento diferenciado entre os dois anos agrícolas deve estar relacionado com a dinâmica da degradação da carga orgânica do lodo de esgoto e, principalmente, com a distribuição das preci pitações pluviométricas ocorridas dentro de cada ano, nas respectivas épocas de amostragem do solo.

Os maiores acréscimos observados para esta variável foram, no anoagrícola 1996/97, aos 30 DAIL e, no ano agrícola 1997/98, aos 150 DAIL. No primeiro ano, nos tratamentos $L a$ e LC, os respectivos acréscimos na CE foram de 995 e 1.153 \% em relação à T. Em 1997/98, tais acréscimos variaram de 393 a $768 \%$. Aumentos na CE de solos tratados com lodo de esgoto também foram observados por Epstein et al. (1976), Stark \& Clapp (1980), Bevacqua \& Mellano (1994), Logan et al. (1997) e Anjos (1999).

O lodo de esgoto utilizado no presente trabalho foi condicionado, no seu processo detratamento, com $\mathrm{FeCl}_{3}$ e $\mathrm{CaO}$. Dessa forma, apresentou em sua composição el evados teores de $\mathrm{Ca}^{2+}$. I sto posto, considerando que foram adi cionadas ao solo, via lodo de esgoto, quantidades anuais de Ca variando de 4,8 a 16,9 $\mathrm{Mg} \mathrm{ha}^{-1}$, parece razoável atribuir os aumentos na CE à presença deste íon no solo. Entretanto, a contribuição de $\mathrm{NH}_{4}^{+}$e $\mathrm{NO}_{3}^{-}$oriundos da mineralização do N-orgânico do resíduo não deve ser desconsiderada.

E pstein et al. (1976) atribuíram os aumentos na CE de solos tratados com lodo de esgoto à grande concentração de $\mathrm{Ca}^{2+} \mathrm{Mg} \mathrm{g}^{2+} \mathrm{eCl}^{-}$presentes na camada de incorporação do resíduo. De forma concordante, Anjos (1999) encontrou correlações significativas entre a CE de solos tratados sucessivamente com lodo de esgoto e teores de $\mathrm{Ca}^{2+}, \mathrm{Mg}^{2+} \mathrm{eK}^{+}$.

Considerando o comportamento da CE dentro das doses de lodo de esgoto no decorrer das amostragens, verificou-se que, nos dois anos agrícolas, à medida que aumentava o tempo da incorporação do resíduo, percebia-seuma tendência significativa de queda em seus valores (Quadro 4). Este decréscimo na concentração salina da superfície do solo provavel mente deveu-se à lavagem de íons solúveis 
ou em suspensão, proporcionado pelo movimento descendente da água de precipitações pluviométricas.

Comportamentos semel hantes foram obtidos por Epstein et al. (1976) e Harding et al. (1985). Esses autores explicaram que o decréscimo verificado na CE do solo no decorrer do tempo foi atribuído à lixiviação de $\mathrm{Ca}^{2+}, \mathrm{Mg}^{2+}$ e $\mathrm{Cl}^{-}$causada pelas chuvas no período de estudo.

A hipótese da lixiviação de íons foi comprovada, neste trabalho, pelas determinações realizadas em amostras de solo coletadas em profundidade, 360 DAIL, nos dois anos agrícolas (Quadro 5). Com base nestes dados, verificou-se que as doses empregadas de lodo de esgoto proporcionaram aumentos significativos da CE até $0,8 \mathrm{~m}$ de profundidade, evidenciando a lixiviação deíons pelo perfil do solo. Comparandoa CE para profundidades, dentro de cada dose do resíduo, observou-se que, ao final de 1996/97, os maiores valores foram para as camadas superficiais de 0-0,2 e 0,2-0,4 m e, para 1997/98, estes ocorreram na camada de 0,2-0,4 m. Todavia, os resultados mostraram a movimentação de íons para as camadas abaixo de $0,8 \mathrm{~m}$, possibilitando, assim, aumentos prováveis e expressivos na CE de camadas mais profundas.

A lixiviação de $\mathrm{Ca}^{2+}, \mathrm{Mg}^{2+}, \mathrm{K}^{+}, \mathrm{Cl}^{-}, \mathrm{NH}_{4}{ }^{+} \mathrm{e} \mathrm{NO}_{3}{ }^{-}$, devida à aplicação de lodo de esgoto e que apresenta potencial para aumentar a CE em subsuperfície, foi verificada por Medalie et al. (1994) eAnjos (1999).
O acúmulo de sais na camada de incorporação do lodo em decorrência da segunda aplicação não foi evidenciado (Quadro 4). Quando comparados os dados de CE obtidos aos 360 DAIL, verificou-se, no ano agrícola 1997/98, que os valores determinados foram menores do aqueles apresentados no ano anterior. Esta observação foi reforçada pela proximidade verificada entre os demais valores de cada ano agrícola, nas respectivas épocas de amostragem. A não-ocorrência de efeito cumulativo pode ser devida ao fato de que, no ano agrícola 1997/ 98, houve preci pita-ções acumuladas em 1.655 mm, ao passo que, no ano anterior, estas foram acumuladas em $1.480 \mathrm{~mm}$.

Considerando a média local de $1.275 \mathrm{~mm}$ anuais (período de retorno de 82 anos), verificou-se, também, que as quantidades de chuvas ocorridas no período experimental foram atípicas. O efeito das precipitações sobre a CE do solo pode ser exemplificado pela comparação entre os valores obtidos 30 dias após cada incorporação de lodo de esgoto. Em 1996/97, nos tratamentos La, Lb e LC, foram detectados valores aproximadamente duas vezes maiores do que aquel es verificados em 1997/ 98. Assim, enquanto, no primeiro ano, a preci pitação acumulada no período foi de $107,4 \mathrm{~mm}$, no ano seguinte foi observado um total de $386,7 \mathrm{~mm}$.

E mbora a CE dosolo, para todas as doses de lodo de esgoto e durante todo o período experimental, tenha se apresentado abaixo de $2.000 \mu \mathrm{S} \mathrm{cm}^{-1}$, val or

Quadro 5. Condutividade elétrica do solo, determinada nas camadas de 0-0,2, 0,2-0,4, 0,4-0,6 e 0,6-0,8 m, 360 dias após incorporação de doses crescentes de lodo de esgoto, nos anos agrícolas 1996/97 e 1997/98

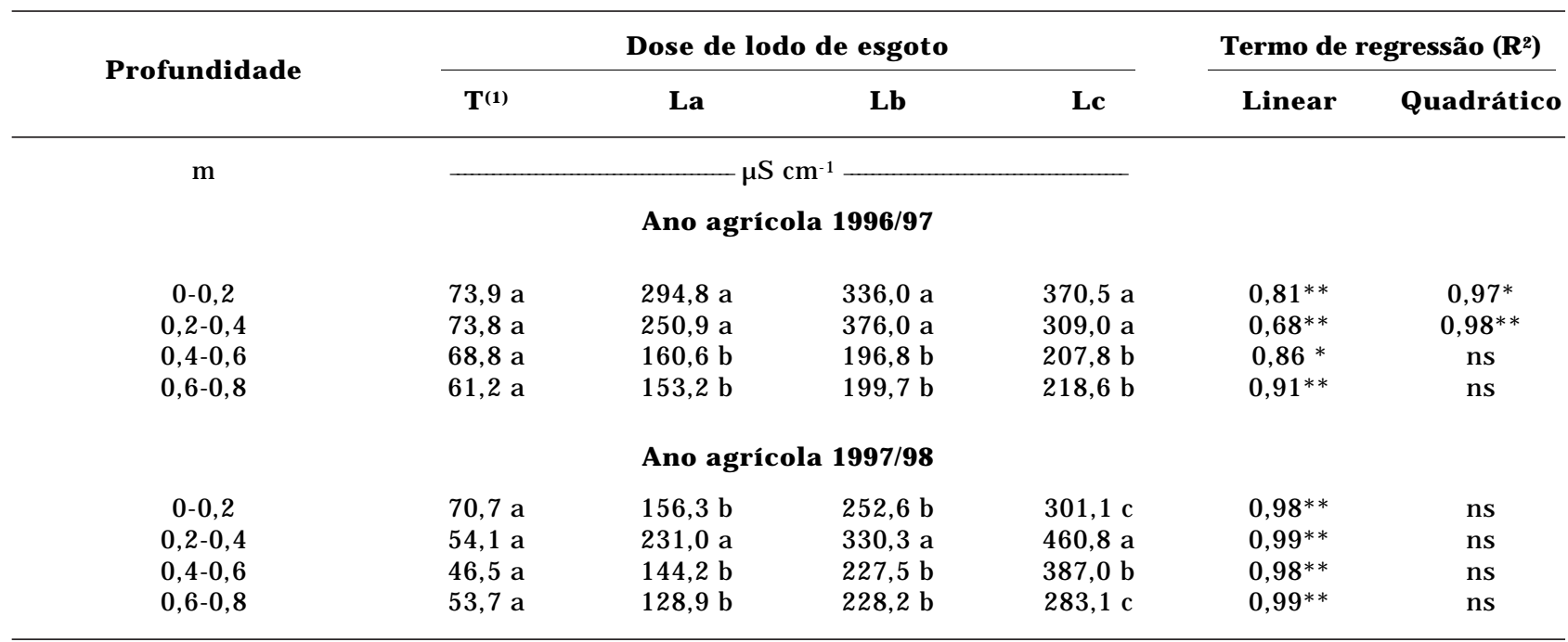

(1) $\mathrm{T}=0, \mathrm{La}=33, \mathrm{Lb}=66, \mathrm{Lc}=99 \mathrm{Mg} \mathrm{ha}^{-1} \mathrm{em}$ 1996/97 e T =0, La =37, Lb =74, Lc = $110 \mathrm{Mg} \mathrm{ha}^{-1} \mathrm{em} \mathrm{1997/98.}$

$*, * *$, ns indicam, respectivamente, que os termos de regressão linear ou quadrática foram significativos a $P \leq 0,05, P \leq 0,01$ ou nãosignificativo pelo teste F. Médias seguidas por letras distintas, em colunas, diferem entre si a P $\leq 0,05$ pelo teste de Tukey - D.M.S. $5 \%=63,3$ (ano agrícola 1996/97) D.M.S. $5 \%$ =69,9 (ano agrícola 1997/98). 
acima do qual os solos são considerados salinos (Richards, 1954), deve-se ressal tar que a adoção deste valor não fornece uma indicação segura quanto ao grau de salinização do sol o no presente experimento, haja vista que este critério foi elaborado com base em determinações da CE em extratos de saturação.

Não obstante, dependendo do tipo de solo e do regime pluviométrico do local, existea possi bilidade deas doses delodo empregadas no presente trabalho ocasionarem, mesmo que temporariamente, problemas desal inidade eseus conseqüentes efeitos no crescimento e desenvol vimento das plantas. De acordo com os dados apresentados (Quadro 5), podese supor que, em condições de déficit hídrico, onde predominariam movimentos ascendentes da água do solo, haveria o afloramento dos sais que se encontram nas camadas subsuperficiais, podendo, assim, causar situações de salinidade, agravando, ainda mais, os problemas de deficiência hídrica.
Bevacqua \& Mellano (1994) encontraram efeitos sazonais do lodo de esgoto sobre a CE do solo, que foram prejudiciais às culturas do alho e alface. Convém salientar que eles aplicaram, durante dois anos, o total acumulado de $74 \mathrm{Mg} \mathrm{ha}^{-1}$ de um composto à base de lodo, taxas e freqüência de aplicações bem inferiores às do presente trabalho, tendo, graças à combi nação com os efeitos climáticos, a $C E$, em extrato de saturação, chegado a picos temporários de $2.440 \mu \mathrm{S} \mathrm{cm} \mathrm{cm}^{-1}$.

Diante dos fatos discutidos, verifica-se a possibilidade de salinização temporária dos solos, dada a utilização pouco cuidadosa do lodo de esgoto; no entanto, ressalta-se que, sobre as plantas de cana-de-açúcar cultivada no experimento, não se observou nenhum efeito de salinidade. Dequalquer maneira, é imprescindível que esta variável seja monitorada econsiderada em estratégias de manejo do resíduo.

Quadro 6. Valores pH do solo, determinados nos tratamentos com doses crescentes de lodo de esgoto, em diversas épocas de amostragem, nos anos agrícolas 1996/97 e 1997/98

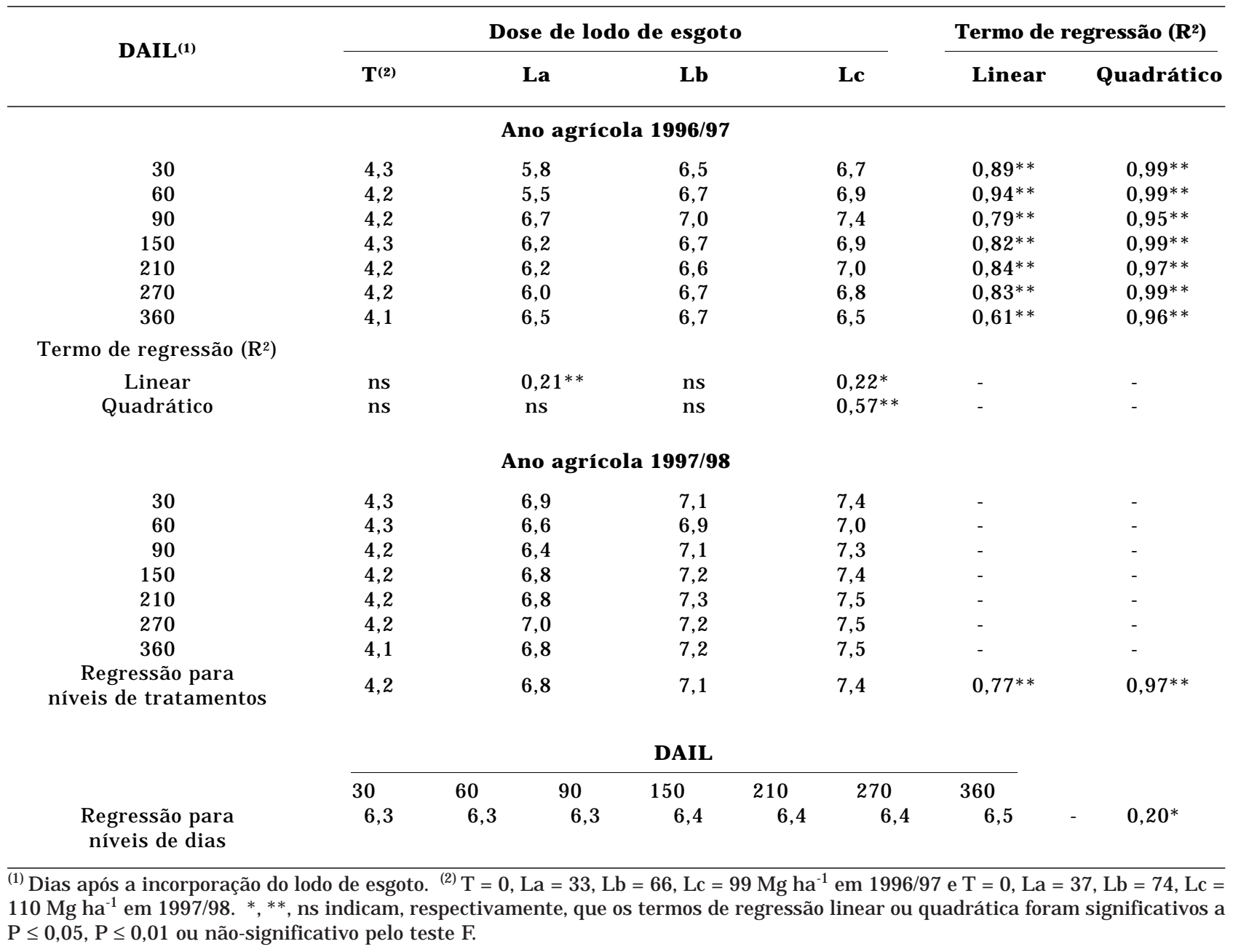


Os valores de $\mathrm{pH}$ do solo (Quadro 6) mostraram interação significativa de tratamentos e épocas de aplicação, para 1996/97, eefeito deépocas, para 1997/ 98. As variações do $\mathrm{pH}$, conforme as épocas de amostragem do solo, foram pouco expressivas e apresentaram baixos coeficientes de determinação. Por outro lado, conforme as doses aplicadas do resíduo, a variável apresentou aumentos de acordo com modelo quadrático, para ambos os anos.

No ano agrícola 1996/97, o pH apresentou acréscimos médios, em relação a T, de 1,9, 2,5 e 2,7 unidades, respectivamente, para as doses de 33, 66 e $99 \mathrm{Mg} \mathrm{ha}^{-1}$ de lodo de esgoto. Em 1997/98, tais acréscimos foram de 2,6, 2,9 e 3,2 unidades, observados após a reaplicação de 37, 74 e $110 \mathrm{Mg} \mathrm{ha}^{-1}$ do resíduo. Para as três doses aplicadas, os acréscimos de $\mathrm{pH}$, em decorrência da segunda aplicação, foram de 0,7, 0,4 e 0,5 unidade. Dessa forma, observa-se que a reaplicação do resíduo proporcionou aumentos relativamente pequenos, quando comparados àqueles do primeiro ano, o que mostra efeito de tamponamento do solo.

A ação neutral izante do lodo de esgoto empregado no presente trabalho é essencial mente devida à sua alcalinidade intrínseca ( $\mathrm{pH}$ em média >10). No processo de tratamento do lodo são adicionadas elevadas quantidades de $\mathrm{CaO}$, uma base forte, com o objetivo de eliminar patógenos efacilitar o processo de desidratação. Trabalhos como os de Barreto (1995), Silva (1995), Sloan \& Basta (1995) e Anjos (1999) mostraram resultados semel hantes, os quais também foram atribuídos à al cal ini dade do material .

A literatura apresenta diversos trabalhos que demonstram a capacidade de lodos de esgoto, sem tratamento prévio com cal, em el evar o $\mathrm{pH}$ de sol os (E pstein et al., 1976; Stark \& Clapp, 1980; Logan et al., 1997). Nestes casos os autores atribuíram o efeito neutralizante às reações envolvidas na degradação da carga orgânica do resíduo. Por outro lado, trabal hos relatados por Simeoni et al. (1984), Pietz et al. (1989) e Dowdy et al. (1991) revelaram, em sol os cultivados, efeitos aci dificantes desses resíduos, os quais foram atribuídos às reações de nitrificação, à provável oxidação de sulfitos eà produção deácidos orgânicos durante a degradação do resíduo.

\section{Capacidade de troca de cátions}

Foram verificados, nos dois anos agrícolas, efeitos significativos de doses de lodo de esgoto e épocas de amostragem sobre a CTC do solo, porém não houve interação desses fatores. O aumento da CTC, considerando as doses do resíduo, seguiu, dentro de todas as amostragens, nos dois anos agrícolas, um comportamento quadrático $\left(\mathrm{R}^{2}=0,92^{* *}\right)$. Análises de regressão apontaram uma tendência crescente nos valores desta variável de acordo com as épocas deamostragem dosolo. E mbora este comportamento tenha apresentado significância estatística, graças à precisão al cançada nas determinações da CTC, as diferenças verificadas para as médias da variável, no decorrer das amostragens em cada ano agrícola, foram extremamente pequenas, de alguns décimos, razão por que não foram consideradas na interpretação e discussão dos resultados.

Examinando o comportamento da CTC no decorrer do período experimental (Figura 2), verificouse, durante os dois anos agrícolas, uma proximidade muito grande entre os valores determinados para os tratamentos La, Lb e Lc. No ano agrícola 1996/97, obteve-se, entre doses, um valor médio ( \pm erro-padrão) de CTC de 44,62 $\pm 0,17 \mathrm{mmol}_{\mathrm{c}} \mathrm{kg}^{-1}$, ao passo que, em 1997/98, tal valor foi de 44,78 $\pm 0,16 \mathrm{mmol}_{\mathrm{c}} \mathrm{kg}^{-1}$. O acréscimo médio proporcionado pel o lodo de esgoto em relação a T foi, em 1996/97, de 12,91 \pm 0,19 $\mathrm{mmol}_{\mathrm{c}} \mathrm{kg}^{-1} \mathrm{e}$, em 1997/98, de 13,52 \pm $0,10 \mathrm{mmol}_{\mathrm{C}} \mathrm{kg}^{-1}$. Portanto, após a segunda aplicação do lodo, obteve-se um incremento de apenas 0,60 \pm $0,23 \mathrm{mmol}_{\mathrm{c}} \mathrm{kg}^{-1}$, o que pode ser considerado desprezível considerando a quantidade de lodo aplicada. Diante destas constatações, éinteressante ressaltar que os efeitos do lodo de esgoto sobre a CTC a pH atual do solo, os quais se manifestaram logo aos 30 DAIL em 1996/97, não refletiram al teração expressiva, mesmo aos 360 DAIL, no ano agrícola 1997/98.

Outro aspecto importante a ser considerado diz respeito à $\mathrm{CTC}$ a $\mathrm{pH} 7,0$ do próprio lodo de esgoto (Quadro 2). Estimativas deacréscimos à CTC do solo, feitas com base nesses valores, da taxa de aplicação do resíduo e da densidade do solo na camada de incorporação revelaram acréscimos potenciais ao redor de 5,4, 10,8 e 16,1 $\mathrm{mmol}_{\mathrm{C}} \mathrm{kg}^{-1}$, respectivamente, em cada ano agrícola, para La, Lb e Lc. Tendo em vista que os valores de $\mathrm{pH}$ observados nos tratamentos com lodo de esgoto variaram, na maior parte do período experimental, de 6,0 a 7,4 (Quadro 6), conclui-se que a estimativa de incrementos para CTC não foi observada no solo em nenhum momento (Figura 2). Portanto, considerando que a CTC a pH 7,0 do lodo de esgoto é devida essencialmente à sua carga orgânica, é possível que esta não seja a principal responsável pelas alterações determinadas na CTC a pH atual do solo.

De maneira geral, os resultados observados no presente trabalho não são concordantes com os verificados por Epstein et al. (1976), Simeoni et al. (1984) e Cavallaro et al. (1993). Esses autores encontraram um comportamento crescente da CTC com a aplicação de lodo de esgoto em doses que variaram de 0 a $240 \mathrm{Mg} \mathrm{ha}^{-1}$ (base seca). Em todos esses trabalhos, o comportamento da CTC foi atribuído aos acréscimos de C-orgânico nos solos proporcionados pelas aplicações do resíduo.

Todavia, énecessário ponderar que E pstein et al. (1976) estimaram a CTC do sol o pela soma de bases, o que pode ter ocasionado valores superestimados, essencialmente porque o lodo de esgoto utilizado 


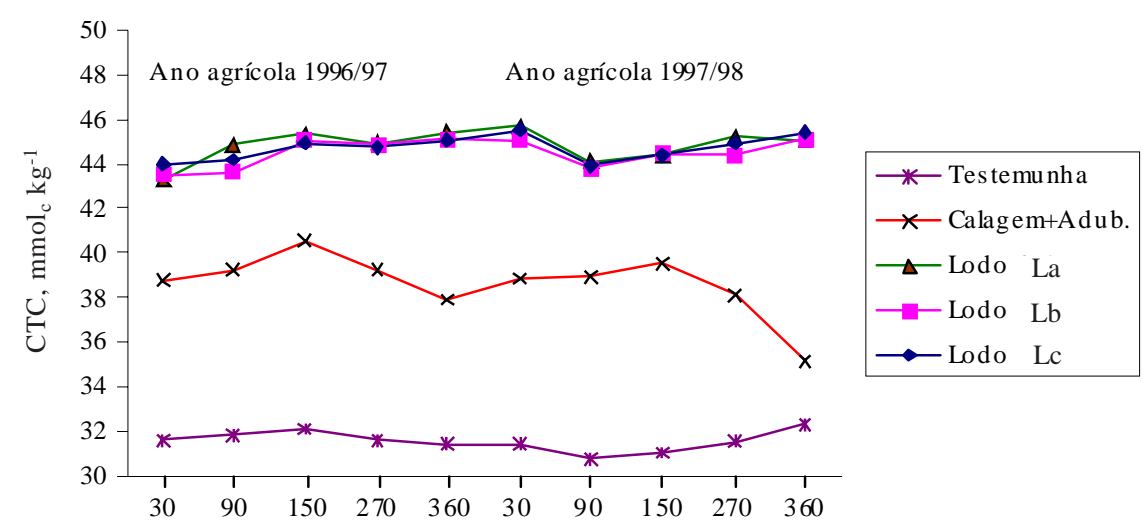

DIAS APÓS A INCORPORAÇÃO DO LODO DE ESGOTO

Figura 2. Capacidade de troca de cátions do solo, nos anos agrícolas 1996/97 e 1997/98, para os tratamentos com doses de lodo de esgoto e calagem + adubação mineral.

$L a=$ lodo dose $A ; L b=$ lodo dose $B ;$ LC = lodo dose C e Lodo = média de La, Lb e Lc.

apresentava elevados teores de Ca e Mg. J á no trabalho de Simeoni et al. (1984), verificou-se que o resíduo empregado não proporcionou alterações significativas no pH do solo e, além disso, as determinações da CTC foram efetuadas com solução alcalina tamponada ( $\mathrm{pH}=8,2)$. Dessa forma, é provável que os resultados observados não sejam reais, mas, sim, potenciais. Cavallaro et al. (1993) determinaram os val ores CTC a pH atual, utilizando o mesmo método empregado no presente trabal ho. Dessa forma, a discordância observada entre os resultados pode ser atribuída às diferenças entre lodos de diferentes origens, as quais são devidas aos processos detratamento e, principalmente, à origem dos esgotos. Esta, por sua vez, define os tipos de compostos orgânicos que preval ecerão na composição do resíduo.

Sabe-se que, em solos sob climas tropicais, o complexo de cargas negativas é essencial mente $\mathrm{pH}$ dependente (Helling et al., 1964), sendo a matéria orgânica o componente principal desse complexo (Fassbender, 1975). Assim, na tentativa deesdarecer melhor a participação das principais variáveis envol vidas na geração de cargas negativas no solo, foram estabel ecidas relações entre CTC epH e entre CTC e teores de C-orgânico do solo (Figura 3).

Para tanto, foram realizadas análises de correlação entre os valores de CTC ao pH atual e valores $\mathrm{pH}$ do solo, considerando as determinações efetuadas separadamente, dentro de cada ano agrícola e para todo o período experimental. Nestas análises foram incluídos os tratamentos CM, T, La, Lb eLc. Verificou-se (Figura 3) que as alterações na CTC apresentaram, de maneira geral, elevada correlação positiva $\left(r=0,91^{* *}\right)$ com as alterações de $\mathrm{pH}$ do solo. Estefenômenojá era esperado, uma vez que, conforme comentado anteriormente, a quase total idade das cargas negativas em sol os tropicais é dependente do $\mathrm{pH}$. No entanto, estecomportamento só foi evidenciado porque o método utilizado para determinar a CTC o fez ao pH natural do solo.

As correlações entre CTC e carbono orgânico do solo foram positivas, embora com coeficientes inferiores aos verificados em rel ação ao pH. Convém salientar que, neste caso, não foi considerado o tratamento CM já que este não causou alterações nos teores originais de carbono orgânico.

Esses resultados são concordantes com Barreto (1995), o qual verificou que os efeitos de doses de lodo de esgoto sobre a CTC determinada a pH atual de uma Areia Quartzosa foram mais bem explicados pelas alterações no pH desse solo.

Diante das relações estabel eci das para o conjunto dedados obtidos, nos anos agrícolas de 1996/97 e 1997/ 98 (F igura 3), é possível verificar alguns fenômenos interessantes. O primeiro del es evidencia queos valores de CTC atingiram um patamar máximo a partir de valores de pH próximos a 6,0 e não apresentaram variações expressivas acima deste valor. Ressaltase que, logo no primeiro ano agrícola, mesmo para a menor dose aplicada de lodo de esgoto, os val ores de pH observados foram próximos ou superiores a 6,0, o que comprova a manifestação do potencial máximo de geração de cargas negativas variáveis do solo.

Com relação ao C-orgânico, é fundamental observar que seus teores nos tratamentos $L a, L b$ e Lc variaram, no decorrer dos dois anos agrícolas, de 8,0 a $16,0 \mathrm{~g} \mathrm{~kg}^{-1}$, uma variação, portanto, de $100 \%$. Apesar desta variação, considerando que os valores de $\mathrm{pH}$ do solo foram favoráveis à intensa manifestação de cargas variáveis da matéria orgânica, é estranho que nenhuma alteração expressiva na CTC tenha sido determinada. Diante dessas observações, fica evidente que os aumentos de CTC, verificados nos tratamentos com lodo de esgoto, nãoforam predominantemente proporcionados pela carga orgânica do resíduo, mas estiveram diretamente relacionadas com o pH do solo. 
Ano agrícola 1996/97
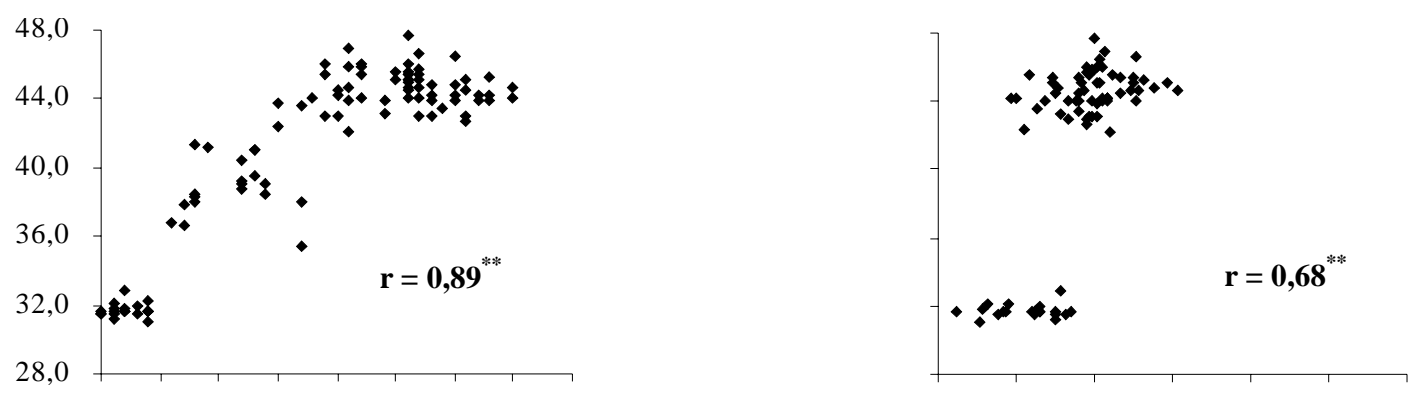

Ano agrícola 1997/98
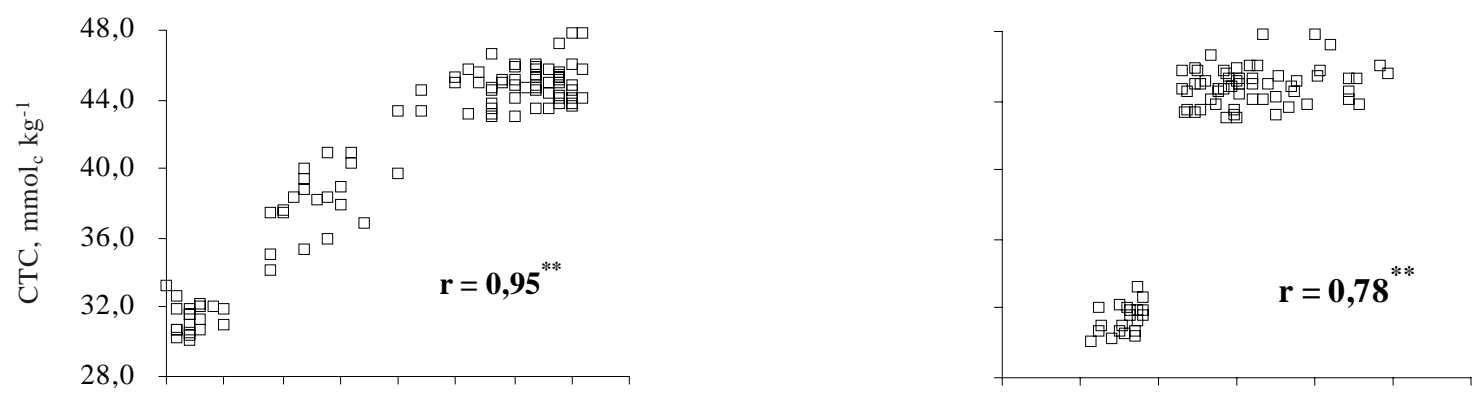

Ano agrícola 1996/97 e 1997/98
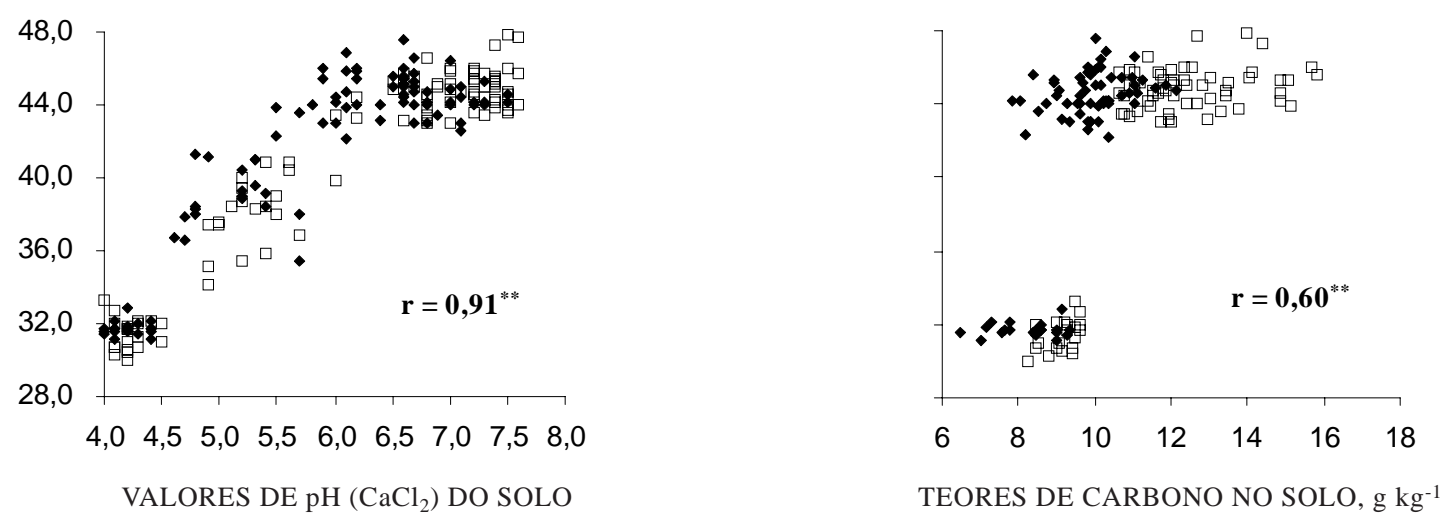

Figura 3. Relações entre CTC e pH, CTC e teores de carbono orgânico do solo, nos anos agrícolas de 1996/ 97(•) e 1997/98 ( $\square)$. ( ${ }^{* *}$ Coeficientes de correlação si gnificativos a $\mathrm{P} \leq 0,01$ pelo teste $t$ ).

Neste contexto, algumas hipóteses podem ser consideradas para explicar os fenômenos observados. A primeira delas parte do princípio de que a contribuição de resíduos orgânicos à CTC dos solos depende primariamente da natureza dos compostos orgâni cos que os constituem (Rodella, 1996). Assim, conforme discutido anteriormente, sabe-se que olodo de esgoto contém uma gama variada de substâncias orgânicas que são recal citrantes, sendo várias delas substâncias apolares, tais como: óleos, graxas, resinas e ceras que, conseqüentemente, por serem insolúveis em água, não geram cargas. Ademais, existem estudos que confirmam o acúmulo dessas substâncias no solo em decorrência de aplicações sucessivas do lodo de esgoto (Hohla et al., 1978). É possível, também, que a CTC a pH 7,0 determinada no resíduo seja devida a uma pequena fração orgânica degradável rapidamente no solo. Dessa forma, considerando que a degradação da carga orgânica do lodo de esgoto ocorre de acordo com um model o cinético de primeira ordem, tal fração teria sido rapidamente degradada, antes mesmo das primeiras amostragens do solo.

Outra possível explicação está diretamente relacionada com o efeito neutralizante do lodo de esgoto. Neste caso, a maior parte do aumento manifestado pela CTC poderia ser atribuída às cargas variáveis da matéria orgânica nativa e da 
fração mineral do solo. Pela difratometria de raios$X$, verificou-se que a fração argila do Latossolo Amarelo distrófico da área experimental era constituída basicamente por caulinita, goethita e hematita (dados não apresentados). Dessa forma, os incrementos de cargas negativas observados com 0 aumento do $\mathrm{pH}$ deveram-se, provavelmente, à desprotonação de grupamentos silanol e aluminol da caulinita e de grupamentos hidroxila das superfícies dos óxidos.

O tratamento CM apresentou valores médios de CTC, durante os dois anos agrícolas, de $38,62 \pm 0,45 \mathrm{mmol}_{\mathrm{c}} \mathrm{kg}^{-1}$, o que representou um acréscimo em relação a T de 7,06 $\pm 0,52$ mmolc kg-1 (Figura 2). O valor do pH médio nos dois anos foi de 5,2 , notratamento $C M$, e de 4,2, emT. Considerando que nenhuma fonte de C-orgânico foi adicionada a este tratamento, verificou-se que apenas a el evação dovalor depH do solofoi capaz deaumentar sua CTC.

\section{CONCLUSÕES}

1. As aplicações de doses crescentes de lodo de esgoto promoveram, em ambos os anos agrícolas, aumentos lineares nos teores de C-orgânico do solo.

2. Os decréscimos de C-orgânico observados no decorrer dos dois anos agrícol as ajustaram-se a um modelo de cinética de primeira ordem. Houve reduções na taxa de decréscimo por ocasião da segunda aplicação do lodo de esgoto, evidenciando o acúmulo de C-orgânico no solo, devido às aplicações sucessivas do resíduo.

3. As aplicações de doses crescentes de lodo de esgoto promoveram, em ambos os anos agrícolas, aumentos na condutividade el étrica do solo, porém não houve indícios de efeitos cumulativos sobre esta variável, em decorrência da segunda apl icação delodo.

4. Houve aumentos no pH do solo com as aplicações de doses crescentes de lodo de esgoto. Por ocasião da segunda aplicação, os incrementos foram menores do que os observados em 1996/97, evidenciando o poder de tamponamento do solo.

5. O lodo de esgoto aumentou a capacidade de troca de cátions do solo, porém não foram verificados aumentos proporcionais às doses aplicadas. As al ter ações na CTC foram mais bem explicadas pelas variações no $\mathrm{pH}$ do que pelos acréscimos de C-orgânico.

\section{AGRADECIMENTOS}

Os autores agradecem à F undação de Amparo à Pesquisa do estado de São Paulo, pel o financiamento do projeto que deu origem a estetrabalho; à Estação Experimental do IAC de Piracicaba (SP), pel o apoio e concessão de uso da área experimental; ao Prof. Dr. Arnaldo Antonio Rodella e aos técnicos de laboratório Lenita M.C. Pacheco eOliveira eJ anaína Truffi, do Depto de Ciências Exatas da USP/ESALQ, pela orientação e colaboração nos procedimentos analíticos.

\section{LITE RATURA CITADA}

AGBIN, N.N.; SABEY, B.R. \& MARKSTROM, D.C. Land application of sewage sludge: $\mathrm{V}$. Carbon dioxide production as influenced by sewage sludge and wood waste mixtures. J. Environ. Qual., 6:446-451, 1977.

ANJ OS, A.R.M. Lixiviação de espécies químicas em Latossolos sucessivamente tratados com biossólido e disponibilidade de metais pesados para plantas de milho. Piracicaba, Escola Superior de Agricultura "Luiz de Queiroz", 1999. 191p. (Tese de Doutorado)

BARRETO, M.C.V. Degradação da fração orgânica de diferentes resíduos e efeitos em algumas propriedades químicas e físicas de dois solos. Piracicaba, Escola Superior de Agricultura "Luiz de Queiroz", 1995. 106p. (Tese de Doutorado)

BEVACQUA, R.F. \& MELLANO, V.J . Cumulative effects of sludge compost on crop yields and soil properties. Comm. Soil Sci. Plant Anal., 25:395-406, 1994.

CAVALLARO, N.; PADILLA, N. \& VILLARRUBIA, J. Sewage sludge effects on chemical properties of acid soils. Soil Sci., 156:63-70, 1993.

CLAPP, C.E.;STARK, S.A.; CLAY, D.E. \& LARSON, W.E. Sewage sludge organic matter and soil properties. In: CHEN,Y. \& AVNIMELECH, Y., eds. The role of organic matter in modern agriculture. Dordrecht, Martinus Nijhoff, 1986. p.209-253.

DEMUYNCK, M.; NYNS, E.J . \& NAVEAU, H. Use of digested effluents in agriculture. In: WILLIAMS, J.H.; GUIDI, G. \& L'HERMITE, P., eds. Long-term effects of sewage sludge and farm slurries applications. London, Elsevier Applied Science, 1985. p.2-13.

DOWDY, R.H.; LATTERELL , J . .; HINESLY, T.D.; GROSSMAN, R.B. \& SULLIVAN, D.L. Trace metal movement in an Aeric Ochraqualf following 14 years of annual sludge applications. J. Environ. Qual., 20:119-123, 1991.

EATON, A.D.; CLESCERI, L.S. \& GRENNBERG, A.E. Standard methods for the examination of water and wastewater. 19.ed. Washington, APHA/AWWA/WEF, 1995. 1082p.

EPSTEIN, E.;TAYLOR, J.M . \& CHANEY, R.L. Effects of sewage sludge and sludge compost applied to soil on some soil physical and chemical properties. J. Environ. Qual., 5:422426, 1976.

FASSBENDER, H.W. Química de suelos, com enfasis em suel os de America Latina. Turrialba, IICA, 1975. 398p.

GILLMAN, G.P. \& SUMPTER, E.A. Modification to the compulsive exchange method for measuring exchange characteristics of soils. Aust. J. Soil Res., 24:61-66, 1986. 
HARDING, S.A.; CLAPP, C.E. \& LARSON, W.E. Nitrogen availability and uptake from field soils five years after addition of sewage sludge. J. Environ. Qual., 14:95-100, 1985.

HELLING, C.S.; CHESTERS, G. \& COREY, R.B. Contribution of organic matter and clay to soil cation-exchange capacity as affected by the $\mathrm{pH}$ of the saturating solution. Soil Sci. Am. Proc., 23:517-520, 1964.

HOHLA, G.N.; J ONES, R.L. \& HINESLY, T.D. The effect of anaerobically digested sewage sludge on organic fractions of blount silt loam. J. Environ. Qual., 7:559-563, 1978.

LOGAN, T.J .; LINDSAY, B.J .; GOINS, L.E. \& RYAN, J.A. Field assessment of sludge metal bioavailability to crops: sludge rate response. J. Environ. Qual., 26:534-550, 1997.

MARSCHNER, H. Mineral nutrition of higher plants. London, Academic Press, 1995. 889p.

MARQUES, M.O. I ncorporação de lodo de esgoto em solo cultivado com cana-de-açúcar. J aboticabal, Faculdade de Ciências Agrárias eVeterinárias, 1996. 111p. (Tesede Livre Docência)

MEDALIE, L.; BOWDEN, B. \& SMITH, C.T. Nutrient leaching following land application of aerobically digested municipal sewage sludge in a northern hardwood forest. J. Environ. Qual., 23:130-138, 1994.

MELO, W.J .; MARQUES, M.O.; SANTIAGO, G.; CHELLI, R.A. $\&$ LEITE, S.A.S. Efeito de doses crescentes de lodo de esgoto sobre frações da matéria orgânica e CTC de um Latossolo cultivado com cana-da-açúcar. R. Bras. Ci. Solo, 18:449455, 1994.

METZGER, L. \& YARON, B. I nfluence of sludge organic matter on soil physical properties. Adv. Soil Sci., 7:141-163, 1987.

MILLER, R.H. Factors affecting the decomposition of an anaerobically digested sewage sludge in soil. J. Environ. Qual., 3:376-380, 1974.

PAGLIAI, M.; GUIDI, G.; LAMARCA, M.; GIACHETTI, M. \& LUCAMANTE, G. Effects of sewage sludge and composts on soil porosity and aggregation. J. Environ. Qual., 10:556$561,1981$.

PIETZ, R.I.; CARLSON, C.R.; PETERSON J r., J .R.; ZENS, D.R. $\&$ LUE-HING, C. Application of sewage sludge and other amendments to coal refuse material: III. Effects on percolate water composition. J. Environ. Qual., 18:174179, 1989.

RICHARDS, L.A. Diagnosis improvements of salineand al caline soils. Washington, Departament of Agriculture, 1954. 160p.
RODELLA, A.A. Métodos de avaliação de materiais orgânicos e efeitos de sua incorporação ao solo sobre a mobilização de macronutrientes. Piracicaba, Escola Superior de Agricultura "Luiz de Queiroz", 1996. 148p. (Tese de Livre Docência)

SETZER, J. Atlas climático e ecológico do Estado de São Paulo. São Paulo, Comissão Interestadual da Bacia ParanáUruguai, 1966. 61p.

SILVA, F.C. Uso agronômico de lodo de esgoto: efeitos em fertilidade do solo e qualidade da cana-de-açúcar. Piracicaba, Escola Superior de Agricultura "Luiz de Queiroz", 1995. 170p. (Tese de Doutorado)

SIMEONI, L.A.; BARBARICK, K.A. \& SABEY, B.R. Effect of small-scale composting of sewage sludge on heavy metal availability to plants. J. Environ. Qual., 13:264-268, 1984.

SLOAN, J.J . \& BASTA, N.T. Remediation of acid soils by using alkaline biosolids. J. Environ. Qual., 24:1097-1103, 1995.

SPIRONELLO,A.; RAIJ , B.van.; PENATTI, C.P.; CANTARELLA, H.; MORELLI, J.L.; ORLANDO FILHO, J.; LANDELL, M.G.A. \& ROSSETO, R. Cana-de-açúcar. In:RAIJ ,B. van.; CANTARELLA, H.; QUAGGIO, J.A. \& FURLANI, A.M.C., eds. Recomendações de adubação e calagem para o Estado de São Paulo. Campinas, Instituto Agronômico de Campinas, 1996. p.237-239.

STARK, S.A. \& CLAPP, C.E. Residual nitrogen availability from soils treated with sewage sludge in a field experiment. J . Environ. Qual., 9:505-512, 1980.

SUMNER, M.E. \& MILLER, W.P. Cation exchange capacity and exchange coefficients In: SPARKS, D.L., ed. Methods of soil analysis: chemical methods. Madison, Soil Science Society of America, 1996. p.1201-1230.

TERRY, R.E.; NELSON, D.W. \& SOMMERS, L.E. Carbon cycling during sewage sludge decomposition in soils. Soil Sci. Soc. Am. J., 43:494-499, 1979a.

TERRY, R.E.; NELSON, D.W. \& SOMMERS, L.E. Decomposition of anaerobically digested sewage sludge as affected by soil environmental conditions. J. Environ. Qual., 8:342-347, 1979b.

UNITED STATES ENVIRONMENTAL PROTECTION AGENCY - USEPA. Title 40 CFR - Part 503. Final rules: Standards for the use or disposal of sewagesludge. Federal Register, 58:9387-9415, 1993.

WALKLEY, A. \& BLACK, I.A. An examination of Degtjareff method for determining soil organic matter and a proposed modification of the chromic acid titration method. Soil Sci. 37:29-38, 1934. 
F.C. OLIVEIRA et al.

R. Bras. Ci. Solo, 26:505-519, 2002 